\title{
KNOWLEDGE, ATTITUDE AND PRACTICES OF NOURISHING MOTHERS ABOUT BREAST FEEDING, ATTENDING URBAN HEALTH CENTRE: A CROSS- SECTIONAL STUDY FROM KISHANGANJ, BIHAR
}

Laxman Kumar1, Kashif Shahnawaz², Gaurav Varma3, Sanjay Kumar Choudhary4, Avisek Gupta ${ }^{5}$, Jitendra Bahadur Singh6,

\section{HOW TO CITE THIS ARTICLE:}

Laxman Kumar, Kashif Shahnawaz, Gaurav Varma, Sanjay Kumar Choudhary, Avisek Gupta, Jitendra Bahadur Singh. "Knowledge, Attitude and Practices of Nourishing Mothers about Breast Feeding, Attending Urban Health Centre: A Cross-Sectional Study from Kishanganj, Bihar". Journal of Evolution of Medical and Dental Sciences 2014; Vol. 3, Issue 07, February 17; Page: 1681-1690, DOI: 10.14260/jemds/2014/2042

ABSTRACT: BACKGROUND: Breast feeding is almost universal, but there are many barriers for proper breast feeding practices. Despite the well-recognized importance of exclusive breast feeding (EBF), this practice is not widespread in the developing countries like India. This is mainly due to lack of understanding and poor adherence of mothers to EBF practices for the first 6 months postpartum. Also, the knowledge and practices of early breast feeding are suboptimal among mothers. OBJECTIVE: To know knowledge, attitude and practices of nourishing rural mothers about breast feeding and their association with demographic variables. MATERIALS AND METHODS: The study was a cross-sectional study, performed in M.G.M.M.C. \& L.S.K Hospital, Kishanganj, Bihar, between December-2013 to January-2014. A total of 129 nourishing mothers of children between 0-2 years of age were selected. Breast feeding knowledge of the mothers was evaluated by giving them a printed structured questionnaire containing different types of questions regarding breast feeding. RESULT: Among 129 nourishing mothers, 100\% knew that mother's milk is the best food for the baby. $71.3 \%$ of the mothers were having knowledge that breast feeding should be started within $1 / 2 \mathrm{hr}$. of birth. 86.8\% of the mothers were having knowledge that EBF should be given upto 6 months. CONCLUSION: This study showed a lack of understanding of the importance of breast feeding and poor adherence to EBF for the first 6 months of baby's life. A lot of gap is present between literate and illiterate mothers in breast feeding practices, which need to be changed.

KEYWORDS: Knowledge, Breast feeding, Attitude, Practice.

INTRODUCTION: Breast-feeding is a cultural norm in India. Irrespective of the fact that breastfeeding in India is almost universal, psychosocial and cultural barriers still exists to early breastfeeding. The exact reasons for this delay are not clearly known. Despite the well-recognized effectiveness of exclusive breast feeding (EBF) for the first 6 months of an infant life for reducing infant mortality, adherence to this practice is not widespread in the developing world. Hence, we conducted this study to assess and evaluate breast-feeding knowledge, attitude and practices and the factors influencing them among women. Promotion of EBF practices for the first 6 months of an infant's life is one of the most effective interventions for reducing infant morbidity and mortality in resource-constrained settings ${ }^{1}$. It is estimated that a breast-fed baby is 14 times less likely to die from diarrhoea, 4 times less likely to die from respiratory disease and 2.5 times less likely to die from other infections than a non-breast fed infant. The World Health Organization (WHO) recommends EBF for the first 6 months of life ${ }^{2,3}$. Numerous studies have shown the advantages of EBF for growth, immunity and prevention of illness in young infants ${ }^{4-6}$. Conversely, several studies have associated 
lack of EBF with high infant mortality \& morbidity from malnutrition and infections 7,8 . Despite the well-recognized importance of EBF, this practice in not widespread in the developing world and the increase at the global level is very modest with much room for improvement ${ }^{9,10}$.

According to National Family Health Survey-3 report, even though the percentage of institutional deliveries are high (90\%), the percentage of children who received breast-feeding in one hour was just $52 \%{ }^{11}$. This signifies poor implementation of breast feeding policies in health care settings and also signifies the missed opportunity to educate the mother and her relatives about the importance of EBF. In the settings, where the practices of institutional delivery is high, the staffs of health care facility should ensure education of the mothers, regarding exclusive breast feeding (EBF), positioning and attachment of infants to the breast before discharge from the health care facility. At the village level, village health nutrition day can be utilized for health education of future mothers and support for breast-feeding mothers ${ }^{12}$. To achieve this, staff of the health care facility should be educated and trained in the importance of EBF, positioning and attachment of breast.

OBJECTIVES: To know knowledge, attitude and practices of nourishing rural mothers about breast feeding and their association with demographic variables.

MATERIALS AND METHODS: The present study was a cross-sectional study, performed in M.G.M. Medical College \& L.S.K Hospital, Kishanganj, Bihar. Institutional Ethical Committee approval was obtained. Study was done between December-2013 to January-2014. A pre-designed, pre-tested study schedule in the form of structured questionnaire was used for collecting data. In this study schedule, both open and close ended questions were kept. Privacy of the individuals was maintained and consent of the mothers was also taken before including them in the study. Those mothers who accepted were included and those who denied were excluded.

Sample size: A total of 129 nourishing mothers of children between 0-2 years of age attending urban health center (Preventive Clinic) of M.G.M.M.C, Kishanganj, for immunization of their children were selected during the study period. They were provided printed structured questionnaire containing questions regarding best food for the baby, time of initiation of breast-feeding after birth, , importance \& knowledge about colostrum, prelacteal feeds, frequency of breast-feeding per day, duration of exclusive breast-feeding, status of breast feeding in baby's illness, and duration of breastfeeding. Structured questionnaire also covered demographic variables that included mother's age, mother's education, father's education, mother's employment status, total family income, family's size, mode of delivery, gender of last child, history of neonatal hospitalization, number of children, and religion of mothers and fathers. Position of the baby during breast-feeding and attachment of the baby's mouth to the breast were assessed by direct observation while feeding. Breast-feeding knowledge of the mother was evaluated.

\section{Criteria of Selection of Participants:}

- Inclusion Criteria:

1. Nursing mothers with child less than two years age group.

2. Given informed consent to participate in study.

- Exclusion Criteria:

1. Known HIV positive serology or AIDS. 
2. Known case of tuberculosis.

3. Taking any anti-cancer drugs.

4. Non-lactating mothers.

Statistical Analysis: This was done in percentage, proportion, compared with chi-square test. Data were primarily analyzed descriptively and then the observations in this study were compiled.

RESULTS: Among 129 nourishing mothers, 100\% knew that mother's milk is the best food for the baby. $71.3 \%$ of the mothers were having knowledge that breast feeding should be initiated within $1 / 2$ hr. of birth (Fig-1). Most of the mothers among them (51.2\%) initiated breast feeding within $1 / 2$ hr. of birth. 31.0\% initiated within $4 \mathrm{hrs}$. $4.7 \%$ within $12 \mathrm{hrs}$. and $7.8 \%$ within $24 \mathrm{hrs}$. (Fig-2). $73.6 \%$ of the mothers believed that colostrum increases the immunity (Fig-3) and 81.3\% were offering colostrum to the baby (Fig-4). Those who were not offering colostrum to their baby were mainly due to their belief that either it is harmful for the baby or baby cannot digest it easily. $71.3 \%$ of the mothers were not offering prelacteal feed to the baby, while $28.7 \%$ of them were giving them, either in the form of honey, water or cow milk (Fig-5). Frequency of breast feeding per day in this study were 6-9 times in $38.8 \%$ of the mothers, $1-5$ times in $31.0 \%, 10-12$ times in $26.4 \%$ and more than 12 times in $3.9 \%$ of the mothers (Fig-6). 86.8\% of the mothers were having knowledge that EBF should be given upto 6 months (Fig-7). $0.8 \%$ of the mothers were giving EBF for $1-2$ months, $7.8 \%$ for $2-4$ months, $34.1 \%$ for 4-6 months \& 43.4\% for more than 6 months duration (Fig-8). 82.2\% of the mothers continued BF, if baby become ill, $8.5 \%$ decreased the frequency of BF and 9.3\% of them stopped BF (Fig-9). Most of the mothers among them believed that BF should be continued for upto 2 yrs. of age.

\section{DISCUSSION:}

Practice of infant-feeding: A global evidence based public health resolution recommends EBF for the 6 months of life and continued BF upto 2 yrs. of age and beyond ${ }^{13}$. In low resource countries, the prevalence of EBF at 6 months is generally low and varies from $9 \%^{14}$ to $39 \%^{15}$. The sizeable gap between $\mathrm{BF}$ practice in developing countries and international recommendations indicate that more attention should be given to the promotion of EBF. EBF promotion, therefore, has become a global health priority with maximum impact on both maternal and child health in developing countries.

Knowledge and Attitudes towards breast feeding: Even though most rural mothers regarded breast feeding as the best for their babies, knowledge about the benefits of breast feeding \& hazards of infant formula feeding was very low.

CONCLUSION: This study showed a lack of understanding of the importance of breast feeding and poor adherence to EBF for the first 6 months post-partum among rural mothers. Also, the knowledge and practices of early breast feeding were suboptimal among the mothers in this rural area of Kishanganj district. A lot of gap is seen between literate and illiterate mothers in breast feeding practices, which need to be changed. The positive changing trends are seen in aspects of colostrum feeding.

RECOMMENDATION: As EBF promotions improve infant survival, more attention in health planning should be given to its promotion. In particular, breast feeding promotion should target the large 
proportion of women, who have missed formal education about infant feeding in school. Greater emphasis should be given at children's and antenatal clinics to educate mothers about the importance of EBF for the first 6 months of their infant's life, the advantages of breast-feeding and potential hazards of feeding a baby with infant formula. Also, Research \& public health efforts like one-to-one "Breast feeding counseling and health education on nutrition" to the mother by health workers should be promoted. Breast feeding counseling with emphasis on correct technique can improve the EBF rates. There is a need for awareness programs regarding breast feeding in this area. To improve the rates of full breast-feeding, specific information about the beliefs \& practices that influence this outcome is needed.

\section{REFERENCES:}

1. Jones G, Steketee RW, Black RE, Bhutta ZA, Morris SS. How many child deaths can we prevent this year? Lancet. 2003 July5; 362 (9377): 65-71.

2. World Health Organization. The optimal duration of Exclusive Breast Feeding: Report of an Expert Consultation. Geneva, Switzerland 28-30 March 2001. Geneva; 2002.

3. World Health Organization. Global strategy for infant and young child feeding. Geneva: World Health Organization; 2003.

4. Arifeen S, Black RE, Antelman G, Baqui A, Caulfield L, Becker S. Exclusive breast feeding reduces acute respiratory infection and diarrhea deaths among infants in Dhaka Slums. Pediatrics. 2001 Oct; 108 (4): E67.

5. Oddy WH, Sly PD, deklerk NH, Landau L, Kendall G, Holt P, Stanley F. Breast feeding and respiratory morbidity in infancy: a birth-cohort study. Arch Dis Child. 2003 March; 88 (3): 224228.

6. Kalanda BF, Verhoeff FH, Brabin BJ. Breast and complementary feeding practices in relation to morbidity and growth in Malawian infants. Eur J Clin Nutr. 2006 Mar; 60 (3): 401-407.

7. Brown KH, Black RE, Lopez De, Romana G, Creed De, Kanashiro H. Infant feeding practices and their relationship with diarrhoeal and other diseases in Huascar (Lima), Peru. Pediatrics. 1989 Jan; 83 (1): 31-40.

8. Almeida RM, De Marins VM, Valle J. Breast feeding, Socio-economic conditions and nutritional status of children younger than 12 months in Brazil. Ann Trop Paediatr.1999 Sep; 19 (3): 257262.

9. Agampodi SB, Agampodi TC, Piyaseeli UKD. Breast feeding practices in a public health field practice area in Sri Lanka: a survival analysis. Int. Breast feed J. 2007 Oct 11; 2:13.

10. Caix, Wardlaw T, Brown DW. Global trends in exclusive breast feeding. Int. Breast feed J. 2012 Sep 28; 7 (1):12.

11. National Family Health Survey- 3 (NFHS-3) Report, Mumbai. International Institute for Population Sciences (IIPS); 2005-2006.

12. Dongre AR, Deshmukh PR, Rawool AP, Garg BS. Where and how breast feeding promotion initiatives should focus its attention? A study from Rural Wardha. Indian J Community Med 2010; 35: 226-9.

13. 54th World Health Assembly: Infant and young child Nutrition (Resolution WHA 54.2), Geneva: World Health Organization; 2001. 


\section{ORIGINAL ARTICLE}

14. ULak M, Chandyo RK, Mellander L, Shrestha PS, Strand TA. Infant feeding practices in Bhaktapur, Nepal: a cross-sectional health facility based survey. Int. Breast feed J. 2012 Jan 10; 7 (1): 1.

15. Lauer JA, Betran AP, Victora CG, de Onis M, Barros AJD. Breast feeding patterns and exposure to suboptimal breast feeding among children in developing countries: review and analysis of nationally representative surveys. BMC Med. 2004 Jul 1; 2: 26.

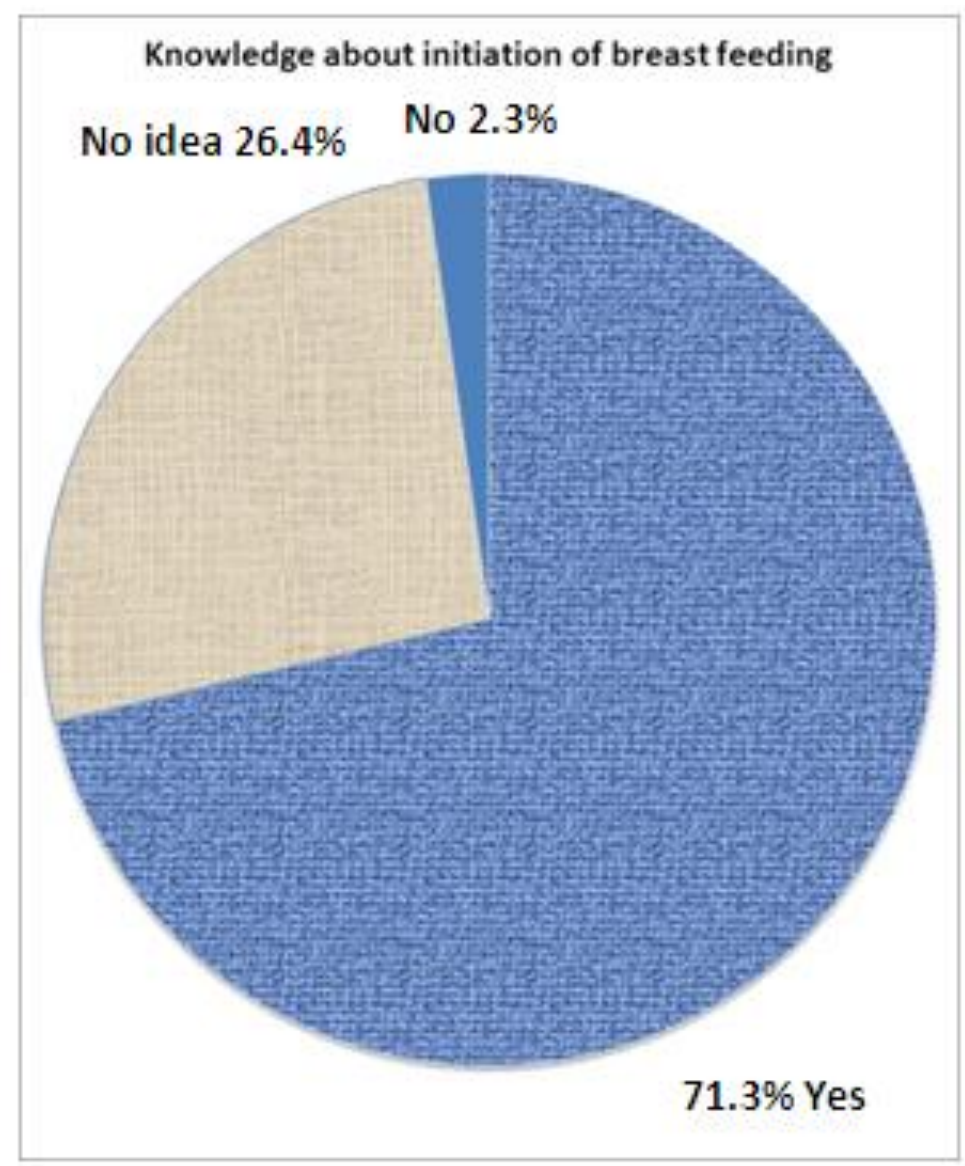

Fig. 1: Breast Feeding within $1 / 2$ hr of birth 


\section{ORIGINAL ARTICLE}

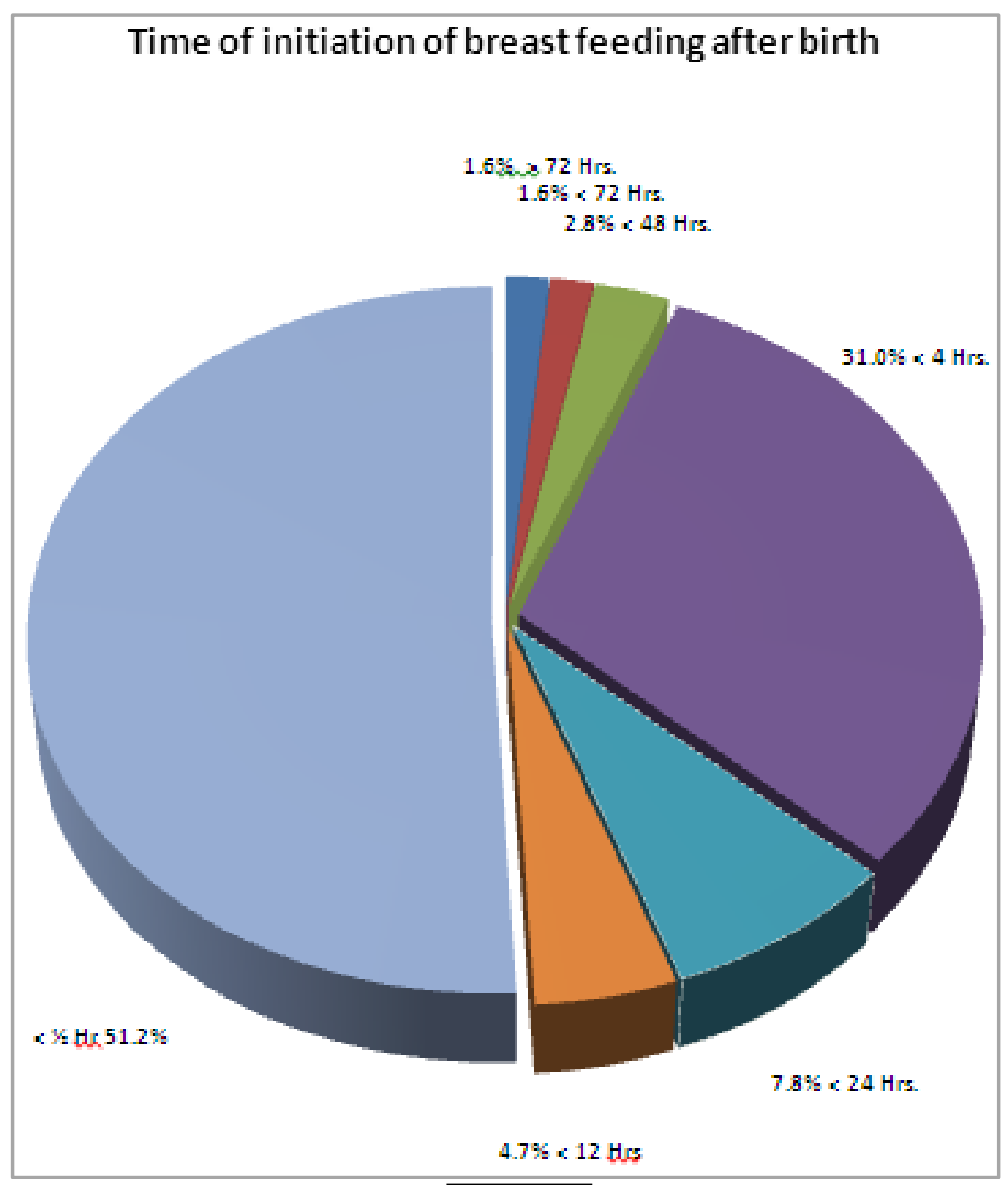

Fig. 2 


\section{ORIGINAL ARTICLE}

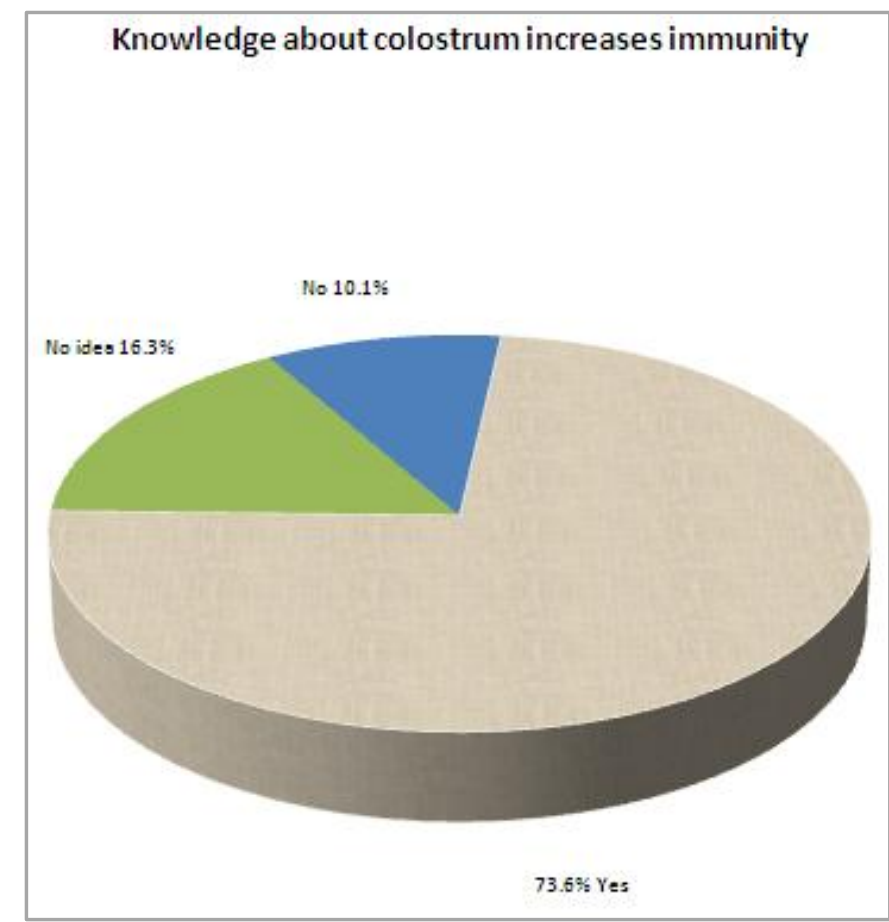

\section{Fig. 3}

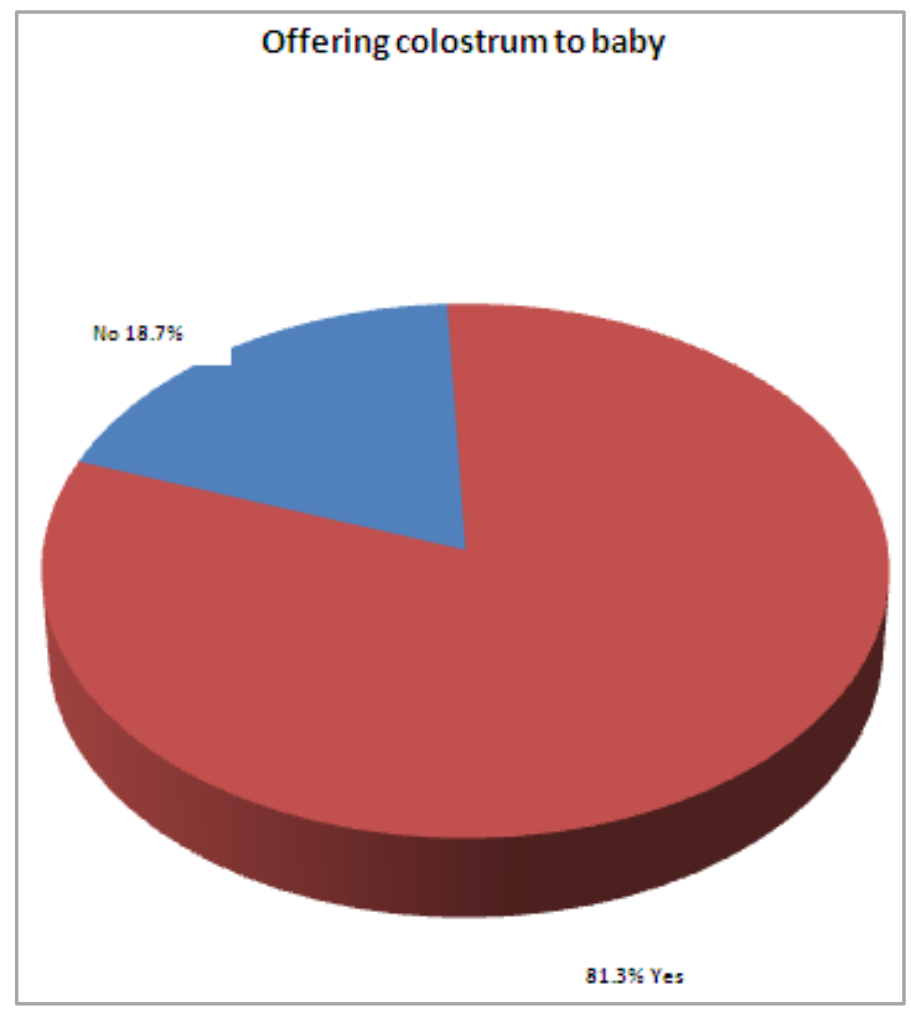

Fig. 4 


\section{ORIGINAL ARTICLE}
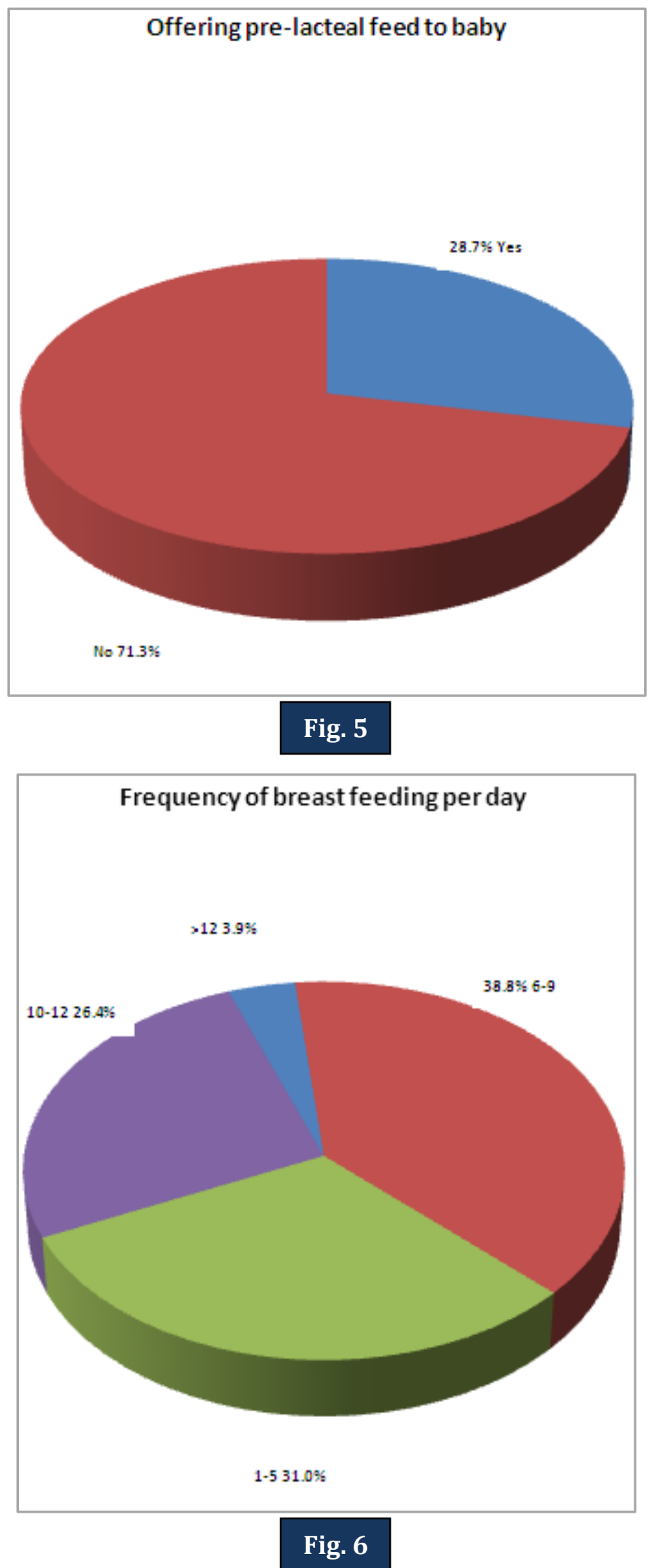


\section{ORIGINAL ARTICLE}

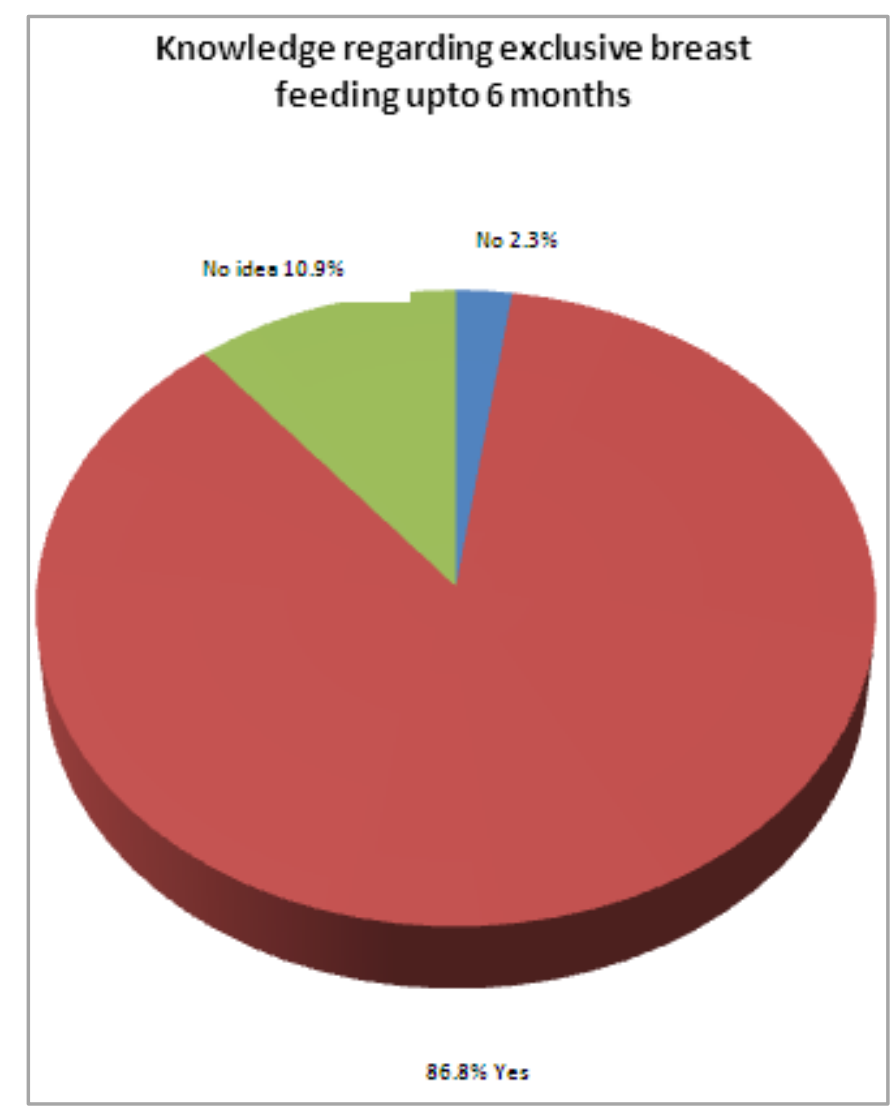

\section{Fig. 7}

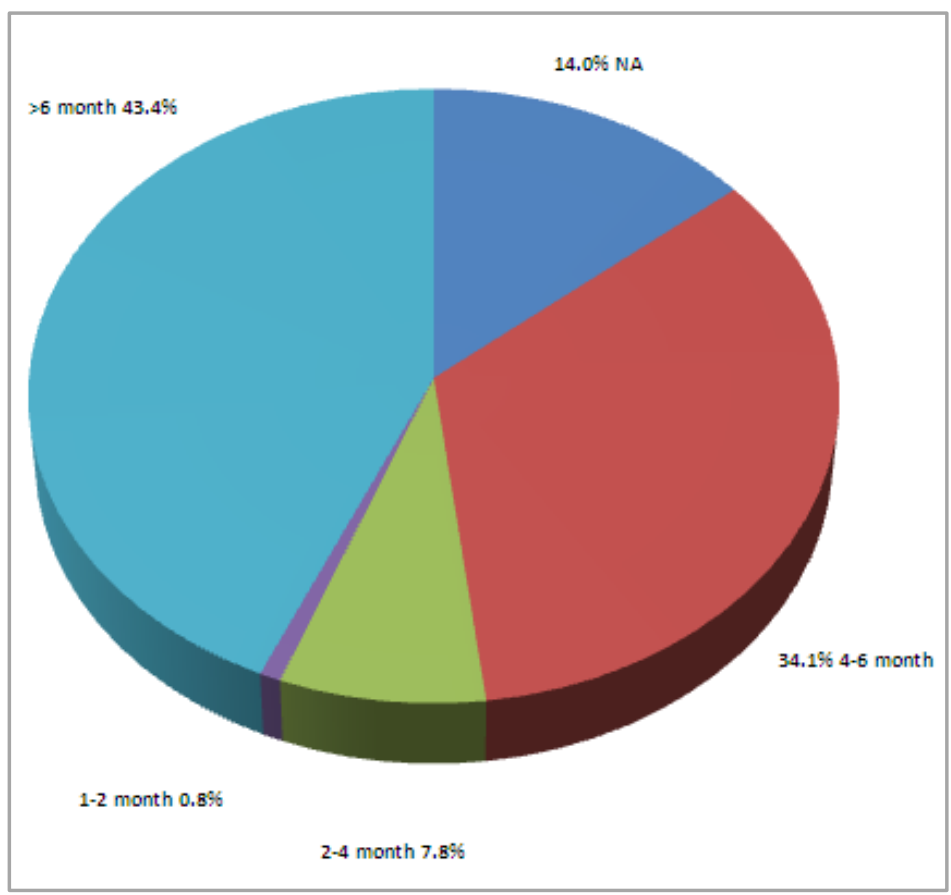

Fig. 8: Duration of exclusive breast feeding 


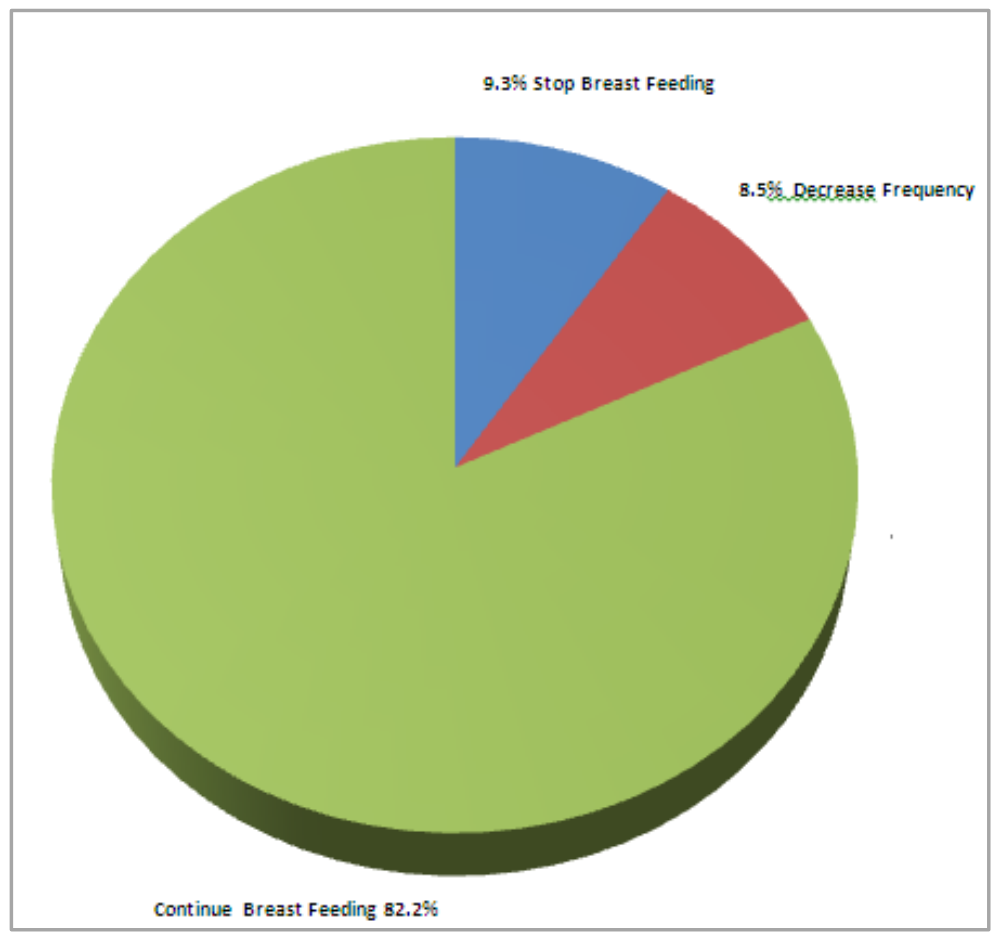

Fig. 9: KAP Gap about Breast Feeding Status of Breast feeding if baby become ill

\section{AUTHORS:}

1. Laxman Kumar

2. Kashif Shahnawaz

3. Gaurav Varma

4. Sanjay Kumar Choudhary

5. Avisek Gupta

6. Jitendra Bahadur Singh

\section{PARTICULARS OF CONTRIBUTORS:}

1. Assistant Professor, Department of Community Medicine, MIMS, Barabanki, UP.

2. Assistant Professor, Department of Community Medicine, MGMMC, Kishanganj.

3. Associate Professor, Department of Community Medicine, MGMMC, Kishanganj.

4. Senior Resident, Department of Community Medicine, IGIMS, Patna.
4. Assistant Professor, Department of Community Medicine, MGMMC, Kishanganj.

5. Tutor, Department of Community Medicine, MGMMC, Kishanganj.

\section{NAME ADDRESS EMAIL ID OF THE CORRESPONDING AUTHOR:}

Dr. Kashif Shahnawaz,

Manhar Road, Chhoti Quazipura,

Dist. Darbhanga, Bihar, PIN - 846004.

E-mail: kashif.shahnawaz98@gmail.com

Date of Submission: 30/01/2014.

Date of Peer Review: 31/01/2014.

Date of Acceptance: 04/02/2014.

Date of Publishing: 13/02/2014. 